\title{
Solvothermal Synthesis of Magnetic Spinel Ferrites
}

\begin{abstract}
At present, solvothermal fabrication method has widely been applied in the synthesis of spinel ferrite nanoparticles (SFNs), which is mainly because of its great advantages such as precise control over size, shape distribution, and high crystallinity that do not require postannealing treatment. Among various SFNs, $\mathrm{Fe}_{3} \mathrm{O}_{4}$ nanoparticles have attracted tremendous attention because of their favorable physical and structural properties which are advantageous, especially in biomedical applications, among which the vast application of these materials as targeted drug delivery systems, hyperthermia, and imaging agents in cancer therapy can be mentioned. The main focus of this study is to present an introduction to solvothermal method and key synthesis parameters of SFNs through this synthesis route. Moreover, most recent progress on the potential applications of $\mathrm{Fe}_{3} \mathrm{O}_{4}$ nanoparticles as the most important compound among the spinel ferrites family members is discussed.
\end{abstract}

Keywords: Application, magnetite, solvothermal synthesis route, spinel ferrites

\section{Introduction}

Spinel ferrite nanoparticles (SFNs) have been in the forefront of nanoscience and nanotechnology in the recent years due to their outstanding properties such as nanometer size, large surface area-to-volume ratio, superparamagnetic behavior, and high saturation magnetization. ${ }^{[1-5]}$ The synthesis of SFNs has attracted a great deal of attention in a variety of research fields ranging from catalysis, ${ }^{[6-8]}$ drug delivery systems, ${ }^{[9,10]}$ ferrofluids, ${ }^{[11]}$ biomedical diagnosis and therapy, ${ }^{[12-15]}$ to energy storage and conversion. ${ }^{[16-20]}$

The spinel structure of SFNs can be described by the formula $\mathrm{MFe}_{2} \mathrm{O}_{4}$, where $\mathrm{M}^{2+}$ and $\mathrm{Fe}^{3+}$ refer to tetrahedral and octahedral cation sites, respectively. The oxygen atoms are arranged in a face-centered cubic (FCC) lattice. Each unit cell contains eight formula units with $\mathrm{O}^{2-}$ anions at the 32 sites and $\mathrm{Fe}^{3+}$ and $\mathrm{M}^{2+}$ cations occupying the octahedral and tetrahedral sites, respectively. ${ }^{[21,22]}$

The magnetic properties of SFNs highly depend on microstructure such as particle size, distribution and morphology of crystallites, changes in the intrinsic divalent and trivalent cation distribution between the tetrahedral and octahedral sites, and control of domains.

This is an open access journal, and articles are distributed unde the terms of the Creative Commons Attribution-NonCommercialShareAlike 4.0 License, which allows others to remix, tweak, and build upon the work non-commercially, as long as appropriate credit is given and the new creations are licensed under the identical terms.

For reprints contact: reprints@medknow.com
The efficient use of SFNs depends on improving their design and controlling their microstructure. The effect of particle size on microstructure is evident. Therefore, understanding the effect of extrinsic factors $(\mathrm{pH}$, temperature, and molecular concentration) on the particle size during production process is imperative. ${ }^{[23]}$

To date, several chemical and physical methods have been developed to produce SFNs such as co-precipitation, sol-gel, organic precursor decomposition, microwave-driven solvothermal process, polymer matrix-mediated synthesis, microemulsion, ionic liquid method, sonoelectrochemical, and solvothermal. ${ }^{[24-32]}$

However, most of the adopted synthesis methods by which SFNs fabricated usually yielded hydrophobic nanoparticles stabilized by nondegradable surfactants that have a low magnetization. It is worth noting that low magnetization impedes SFN applications, especially in bio-related fields, where water-dispersible particles with high magnetization saturation (Ms) are in demand. Therefore, much effort has focused on the development of hydrophilic SFNs with controllable sizes, fast magnetic response, and desirable surface properties. $^{[31,33]}$

Solvothermal fabrication method (SFM) refers to the synthesis through chemical

How to cite this article: Rafienia M, Bigham A, Hassanzadeh-Tabrizi SA. Solvothermal synthesis of magnetic spinel ferrites. J Med Sign Sens 2018;8:108-18.

\section{Mohammad Rafienia, Ashkan Bigham ${ }^{1}$, Seyed Ali Hassanzadeh- Tabrizi ${ }^{1}$}

Biosensor Research Center, Isfahan University of Medical Sciences, Isfahan, Iran, ${ }^{1}$ Advanced Materials Research Center, Department of Materials Engineering, Najafabad Branch, Islamic Azad University, Najafabad, Iran
Address for correspondence: Dr. Mohammad Rafienia, Biosensor Research Center, Isfahan University of Medical Sciences, Isfahan, Iran. E-mail:m_rafienia@med.mui. ac.ir

Website: www.jmss.mui.ac.ir DOI: 10.4103/jmss.JMSS_49_17 
reactions in nonaqueous solution, and it can greatly increase the reactivity and solubility of reactants. By SFM, chemical reactions are carried out in sealed containers and solvents can be brought to temperatures well above or near their boiling points by the increase of autogenous pressures resulting from heating. ${ }^{[34,35]}$ The SFM is A nontoxic and very simple solution process and allows for the precise control over the size, shape distribution, and high crystallinity of SFNs, which do not require postannealing treatment. ${ }^{[36-39]}$ These characteristics can be altered by changing certain experimental parameters, including reaction temperature, reaction time, solvent type, surfactant type, and reductant type. Relying on Teflon-lined autoclaves as reactors, SFM has the capacity to become a scale-up process. ${ }^{[40]}$ Herein, we tend to introduce SFM by which SFNs are produced, and to the best of our knowledge, no reviews on the solvothermal fabrication of SFNs have recently been published.

Therefore, we have collected some important and original findings that are reported for synthesis of SFNs via solvothermal method. The SFM has some key synthesis parameters such as temperature, reaction time, solvent, capping agents, and reductant effects that in the first part are discussed. In the second part, we summarize the most relevant studies about fabrication and potential applications of magnetite $\left(\mathrm{Fe}_{3} \mathrm{O}_{4}\right)$ as the most important magnetic ferrites through solvothermal method.

\section{The Mechanism for the Formation of Spinel Ferrite Nanoparticles via Solvothermal Route}

The probable mechanism for the formation of SFNs can be divided into two stages: first, nucleation from the atoms formed by the reduction of metal salts, and second, the growth of nuclei into nanospheres through a process of atomic growth. These two stages of SFNs fabrication can be changed by controlling thermodynamic and kinetic parameters. Under thermodynamic control, minimization of total surface energy of SFNs is occurred. ${ }^{[41-43]}$

In practical reaction conditions, decreasing in surface energy of SFNs is performed by adsorption of surfactants on SFNs. These surfactants may alter the surface energy of SFNs and prevent them from aggregation or agglomeration during the growth process. Moreover, using kinetic control approaches such as reaction temperature and reactant concentrations, the growth rate of atoms onto different particle size distribution and morphology could be manipulated. It is noteworthy that during synthesis of SFNs, the Ostwald ripening process plays an important role in the formation of nanospheres for all systems. According to the Ostwald ripening mechanism, crystalline particles grow into crystalline nuclei, which aggregate isotropically to form spherical SFNs in nonaqueous solution (in the case of solvothermal method) and further to nanospherical crystallites. During the SFN growth, the smaller, the less crystalline particles will be dissolved gradually, while the larger, the more crystalline particles will grow bigger. Finally, the core can grow gradually to form a solid sphere. As the reaction continues, $\mathrm{MFe}_{2} \mathrm{O}_{4}$ nanosphere will be formed at the end. ${ }^{[44,45]}$

Here, we summarize various key parameters that govern the morphologies of SFNs using solvothermal synthesis methods, namely (1) reaction time and temperature, (2) solvent effects, (3) capping agent effects, and (4) reductant effects.

\section{Reaction time and temperature}

Based on reaction temperature, SFM is classified into two groups: subcritical and supercritical synthesis reactions. When the temperature is in the range of $100^{\circ} \mathrm{C}-240^{\circ} \mathrm{C}$, it is called subcritical synthesis reaction which is more applicable to industrial and laboratory operations. The SFM of SFNs is a typical subcritical synthesis. In the supercritical synthesis, the temperature could reach $1000^{\circ} \mathrm{C}$ and the pressure could reach $0.3 \mathrm{GPa}^{\left[{ }^{46]}\right.}$

Due to increasing temperature, the viscosity of synthetic media decreases and the dynamism of dissolved ions and molecules will be increased under SFM conditions than at ambient temperature. Using the special properties of solvents such as water or organic solvents and other reactants under supercritical temperature and pressure, various syntheses with specific properties could be conducted, resulting in the production of vast crystalline materials with interesting structures. ${ }^{[47,48]}$ In the case of SFNs, Penchal Reddy and Mohamed ${ }^{[45]}$ reported that by increasing the reaction temperature to higher degrees, the average particle size and agglomerations' degree of SFNs tend to increase. On the other hand, the value of $\mathrm{Ms}$ is related to the crystallite size of the nanoparticles, i.e., the larger the crystallite size, the higher value of Ms. As can be seen in Figure 1, the grain size and crystallinity of ferrite-based particles increased significantly with increasing

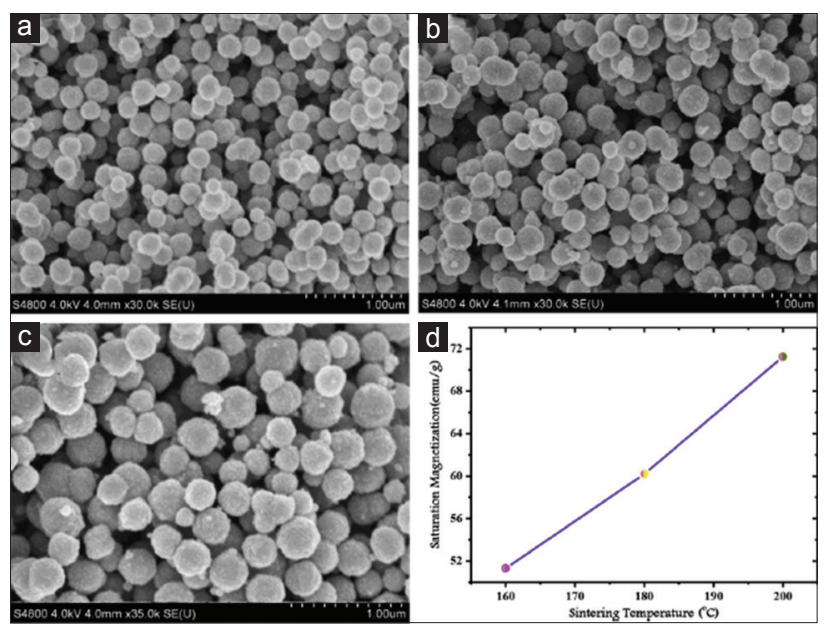

Figure 1: SEM images of $\mathrm{CoFe}_{2} \mathrm{O}_{4}$ solvothermal treated at temperatures (a) $160^{\circ} \mathrm{C}$, (b) $180^{\circ} \mathrm{C}$, (c) $200^{\circ} \mathrm{C}$ for $16 \mathrm{~h}$ and (d) dependence of saturation magnetization on sintering temperature. SEM - Scanning electron microscopy 
reaction temperature, and the particle size becomes well uniform at higher reaction temperatures. Moreover, the Ms data as shown in Figure 1d clearly indicate that as the reaction temperature increases, the magnetic moment is also increased, which is mainly because of an increase in the grain size and crystallinity of SFN samples. The effect of particle size on magnetic properties can be explained by the surface spin disorder in SFNs. Kodama et al. ${ }^{[9]}$ reported that multiple configuration for any orientation of the core magnetization is an important parameter that reduces the magnetic moment and it depends on magnetic ferrite's particle size.

The effect of reaction time is considered as an important parameter as well. At the beginning stages of SFN reactions, the concentration of metal atoms into the reaction medium increases beyond saturation concentration but no nuclei form. As the concentration reaches the nucleation concentration, nuclei form quickly and concentration of dissolved ions decreases below the nucleation concentration. Then, the reaction enters growth stage. At the initial stage of growth, SFNs often show poorly defined shapes. As the reaction time increases, the SFNs tend to evolve into a regular shape. Further increase of reaction time may lead to the reconstruction of SFNs and Ostwald ripening process. Consequently, morphology evolution frequently happens in SFM as reaction time increases, enabling the synthesis of SFNs with different particle size distribution and magnetic behavior simply by changing reaction time in many cases. In general, thermodynamically favored products are more likely obtained after long reaction time. The effect of reaction time on the formation process of $\mathrm{MgFe}_{2} \mathrm{O}_{4}$ through SFM is studied by Kang et al. ${ }^{[4]}$ Figure 2 shows the scanning electron microscopy (SEM) images of samples at different reaction time $(10 \mathrm{~min}, 2 \mathrm{~h}, 8 \mathrm{~h}$, and $11 \mathrm{~h})$. It is found that after $10 \mathrm{~min}$, the structure of $\mathrm{MgFe}_{2} \mathrm{O}_{4}$ is composed of many sheet-like particles. As the reaction proceeded, uniform spheres are formed.

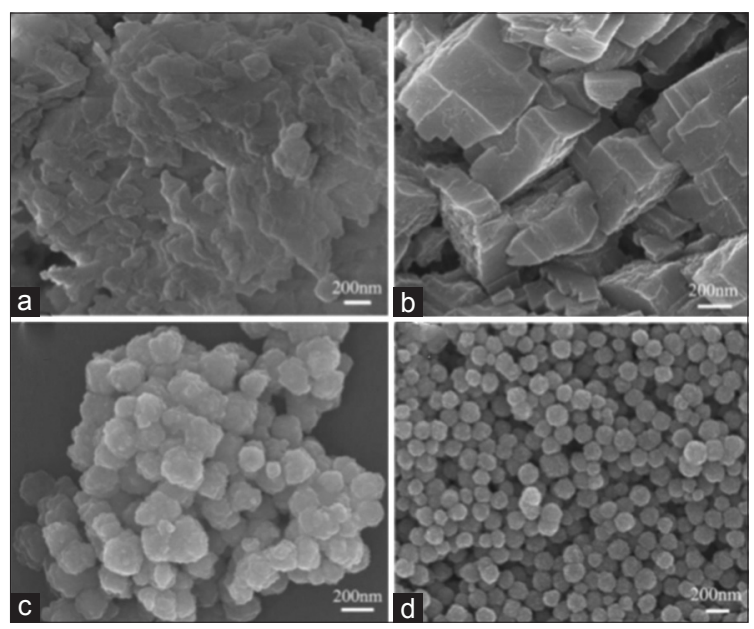

Figure 2: SEM images of $\mathrm{MgFe}_{2} \mathrm{O}_{4}$ materials collected for different time intervals of (a) $10 \mathrm{~min}$, (b) $2 \mathrm{~h}$, (c) $8 \mathrm{~h}$, and (d) $11 \mathrm{~h}$. SEM - Scanning electron microscopy

\section{Solvent effects}

Reaction medium has a significant effect on any hydrothermal or solvothermal system. Solvents in SFM exhibit unique properties, especially under supercritical conditions. The reaction equilibriums and reaction kinetics are directly related to interactions of solvents with reactants, intermediates, and products. In SFM, some solvents can play the role of structure modulators through their interactions with synthesized nanoparticles, and when surfactants are used in reaction medium, solvents can influence micelle structures. In addition, the organic solvent not only acts as a reaction medium but also can serve as a dissolver or partially dissolver of reactants to form solvent-reactant complex, which will affect the chemical reaction rate. The classification of organic solvent is usually based on solvent properties, such as molecular weight (Mr), density (d), melting point (mp), boiling point (bp), dielectric constant, and solvent polarity. Among these factors, solvent polarity, which is defined as the sum of the interaction of solvent and reactants including Coulomb force, induction force, dispersion force, H-bond, and charge transport force, has the key role to describe the solvation property of solvent in SFM ${ }^{[50]}$ In the case of SFNs, different solvents such as water, ${ }^{[51,52]}$ polyols, ${ }^{[31,53]}$ and oleylamine $(\mathrm{OAm})^{[54,55]}$ and mixed solvents have often been employed as solvents because of their compatible properties with common reactants. Among them, polyols (such as ethylene glycol [EG] with strong reducing capability and a relatively high bp) have been also extensively investigated as both solvent and reducing agent to provide monodisperse SFNs. ${ }^{[56]}$ Monodisperse magnetic nanoparticles (MMNs) have been synthesized in organic solution, such as OAm, which has poor solubility in aqueous solution. In these approaches, the long hydrocarbon chains of the surfactants are indispensable to prevent agglomeration of MMNs. In the presence of hydrophobic solvents such as OAm, these MMNs often are coated with the hydrophobic long aliphatic surfactants, which restrict their biological applications. ${ }^{[57]}$ To avoid the hydrophobicity of products, researchers have used water-soluble EG as solvent due to the presence of hydroxyl groups featuring mild reducing properties. Moreover, EG can serve as a surfactant, which has the ability to prevent particles against agglomeration. ${ }^{[31,33]}$

\section{Capping agent effects}

Extensive efforts have been devoted by experimentalists to control the factors involved in morphological variations of SFNs to develop defined structure with specified physical and chemical properties. ${ }^{[58]}$ It has been proved by many researchers ${ }^{[59-63]}$ that capping agents such as surfactants play a key role in controlling morphology of MMNs because of their soft-template effect, their ability to modify the chemical kinetics, and simple maneuverability. It is observed that using different surfactants/capping agents can make important effect on the particle size of SFNs in SFM, 
and many surfactants such as polyethylene glycol (PEG), ${ }^{[31]}$ polyvinylpyrrolidone (PVP), ${ }^{[52,61]}$ polyacrylic acid (PAA), ${ }^{[60]}$ sodium dodecyl sulfate (SDS), ${ }^{[53,57,63]}$ and cetyltrimethylammonium bromide $(\mathrm{CTAB})^{[64]}$ have been used as soft templates to synthesize magnetic nanoparticles. As discussed above, the growth of a nanostructure is due to Ostwald ripening process. This process is dominant at nanometer level. It is reported that the capping agents such as surfactants, as they directly modify the nanoparticle surface, can largely influence this process and hinder the excessive growth of nanoparticles in SFM. Moreover, the molecular weight of surfactants makes a remarkable contribution to the assembly behaviors of the nanoparticles. In bottom-up synthesis methods, self-assemblies of SFNs in ordered and intended structures are governed by the balance of forces due to van der Waals interaction, capillary interaction, surface tension, and hydrophobic interaction and H-bonding effect. ${ }^{[64]}$ Liu et al. have used CTAB as a surfactant to synthesize $\mathrm{Fe}_{3} \mathrm{O}_{4}$ nanocrystals and found that the grain size of magnetite nanocrystals remarkably decreased due to the capping function of CTAB bimolecular layer. Moreover, the particle size distribution and dispersibility of the magnetite microspheres are improved with the increase of CTAB. To find the optimum surfactant concentration, they investigated the CTAB concentration increasing from 0.034 to $0.136 \mathrm{~mol} / \mathrm{L}$. Figure 3 shows transmission electron microscopic (TEM) images of the SFN samples obtained in different CTAB concentrations. As can be seen in Figure 3a, the SFNs exhibit irregular shape, wide particle size distribution, and poor dispersibility in the absence of CTAB. By increasing the amount of CTAB to $0.034 \mathrm{~mol} / \mathrm{L}$, there are small amounts of MMNs, but most particles still show poor morphology. Eventually, when the $\mathrm{CTAB}$ concentration was $0.102 \mathrm{~mol} / \mathrm{L}$, the produced microspheres exhibited apparent monodispersity with an average diameter of $230-250 \mathrm{~nm} \cdot{ }^{[64]}$

Using appropriate surfactants, it is possible to make a great control on different interactions that exist in SFM medium, and it seems that exploiting these mechanisms using suitable capping agents is an interesting and challenging aspect in the synthesis of SFNs.

\section{Reductant effects}

The next significant parameter to influence the morphology of SFNs through SFM is the reductant. Different reductants

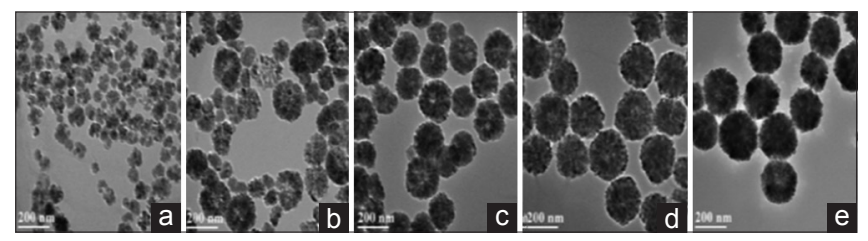

Figure 3: TEM images of the $\mathrm{Fe}_{3} \mathrm{O}_{4}$ particles obtained using different CTAB concentrations: (a) $0 \mathrm{~mol} / \mathrm{L}$; (b) $0.034 \mathrm{~mol} / \mathrm{L}$; (c) $0.068 \mathrm{~mol} / \mathrm{L}$; (d) $0.102 \mathrm{~mol} / \mathrm{L}$; and (e) $0.136 \mathrm{~mol} / \mathrm{L}$ (temperature $=200^{\circ} \mathrm{C}$, time $=12 \mathrm{~h}$ ). TEM - Transmission electron microscope; CTAB - Cetyltrimethyl ammonium bromide such as hydrazine hydrate, $\mathrm{NaOH}, \mathrm{KOH}, \mathrm{NH}_{4} \mathrm{OH}$, and acetates to produce SFNs are used. Most of these reductants have strong reducing power that leads to fast reduction, and particle size and shape of SFNs are usually difficult to control. ${ }^{[88,62,63]}$ The reduction kinetics is adjustable by changing their concentrations or reaction temperatures. To better control on the rate of reduction, a range of milder reductants have been used. Among these reductants, it is observed that acetates as electrostatic stabilizers are widely used as a reducing agent in the synthesis of SFNs. ${ }^{[65]}$ It is proved by Nonkumwong et al. ${ }^{[58]}$ that the size, shape, and degree of agglomeration of MMNs $\left(\mathrm{MgFe}_{2} \mathrm{O}_{4}\right)$ highly depend on the type of reductants. Moreover, they have shown that using stronger reductants such as $\mathrm{NaOH}, \mathrm{KOH}$, and $\mathrm{NH}_{4} \mathrm{OH}$ leads to increase reaction rate, resulting in the occurrence of some undesired phase(s), but, in the presence of $\mathrm{CH}_{3} \mathrm{COONa}$. $3 \mathrm{H}_{2} \mathrm{O}(\mathrm{NaAc})$ as a reductant, pure phase of superparamagnetic MMNs $\left(\mathrm{MgFe}_{2} \mathrm{O}_{4}\right)$ with desired morphology is obtained. The TEM images of $\mathrm{MgFe}_{2} \mathrm{O}_{4}$ nanoparticles that synthesized by various reductants are shown in Figure 4.

\section{Case Study of Spinel Ferrite Nanoparticles}

In the next section, we will focus on some studies that fabricated $\mathrm{Fe}_{3} \mathrm{O}_{4}$ through $\mathrm{SFM}$ as the most studied one which has favorable electric and magnetic properties. In addition, their results related to morphology, magnetic behaviors, and potential applications of magnetite are discussed.

\section{Magnetite $\left(\mathrm{Fe}_{3} \mathrm{O}_{4}\right)$}

Crystal structure of $\mathrm{Fe}_{3} \mathrm{O}_{4}$ follows a cubic inverse spinel pattern based on Fd-3m space group with alternating octahedral and tetrahedral-octahedral layers. In each unit cell of magnetite, the oxygen atoms form an FCC closed packing and both tetrahedral and octahedral sites are occupied by iron ions, in which $\mathrm{Fe}^{3+}$ ions occupied

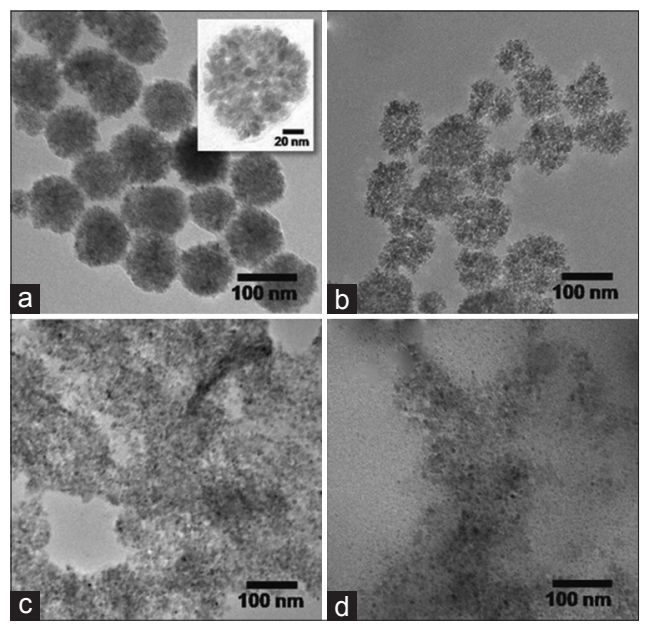

Figure 4: TEM images of $\mathrm{MgFe}_{2} \mathrm{O}_{4}$ particles synthesized at $180^{\circ} \mathrm{C}$ for $12 \mathrm{~h}$ using (a) $\mathrm{CH}_{3} \mathrm{COONa}$, (b) $\mathrm{NH}_{4} \mathrm{OH}$, (c) $\mathrm{KOH}$, and (d) $\mathrm{NaOH}$ as bases. TEM - Transmission electron microscope 
tetrahedral sites and octahedral positions are occupied by eight $\mathrm{Fe}^{2+}$ ions and eight $\mathrm{Fe}^{3+}$ ions. ${ }^{[66]}$ After the Sugimoto group has prepared $\mathrm{Fe}_{3} \mathrm{O}_{4}$ nanoparticles with a narrow size distribution in the early $1980 \mathrm{~s},{ }^{[67]}$ various synthetic routes to fabricating MMNs have been applied. ${ }^{[68-75]}$ However, the water dispersal of SFNs that synthesized by these methods was weak, which leads to the limitation of their biomedical applications. ${ }^{[33]}$ In 2005, Deng et al. ${ }^{[31]}$ reported the chemical synthesis of single-crystalline magnetic microspheres including magnetite via SFM. They have used iron chloride as a ferrite precursor, EG as a reaction medium, and $\mathrm{NaAc}$ and PEG as a reducing agent and surfactant, respectively. They found that by increasing the reaction time from 8 to $72 \mathrm{~h}$, with constant precursor concentration and temperature $\left(200^{\circ} \mathrm{C}\right)$, microsphere diameters are observed to be increased from 200 to $800 \mathrm{~nm}$. The Ms value of single-phase magnetite is reported about $81.9 \mathrm{emu} / \mathrm{g}$. Two years later, Xiongs group synthesized magnetite nanocubes with relatively narrow size distribution around $50 \mathrm{~nm}$ in a water-alcohol mixed solvent solution. They used ferrocene $\left(\mathrm{n}_{-}-\mathrm{C}_{2} \mathrm{H}_{5}\right)_{2} \mathrm{Fe}$ as a precursor, PVP as a surfactant, mixture of distilled water and alcohol as solvent, and hydrogen peroxide as a reducing agent. Then, the precursor solution is transferred to the Teflon-lined stainless autoclave and temperature was put at $230^{\circ} \mathrm{C}$ for $24 \mathrm{~h}$. As can be seen in Figure 5, the SEM image [Figure 5a] shows that the as-synthesized $\mathrm{Fe}_{3} \mathrm{O}_{4}$ has a sphere-like shape with the average size of $68 \pm 10 \mathrm{~nm}$, but it is proved by TEM image [Figure 5b] that morphology of the as-synthesized $\mathrm{Fe}_{3} \mathrm{O}_{4}$ with the average size of $48 \pm 8 \mathrm{~nm}$ is cube-like. ${ }^{[52]}$

As discussed before, using different kinds of surfactants in SFM has attracted research interests, which are due to reducing the size of $\mathrm{Fe}_{3} \mathrm{O}_{4}$ nanocrystals and improving monodispersion of secondary aggregates. Ge et al. ${ }^{[60]}$ have synthesized magnetite particles with controllable diameter using PAA as surfactant. Similarly, nanoporous and MMNs

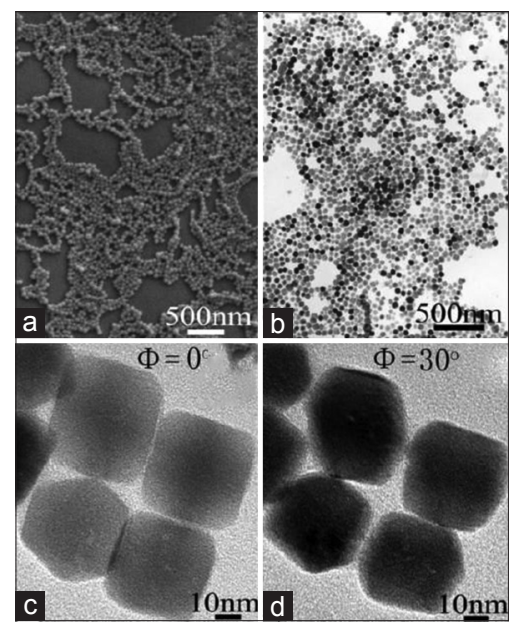

Figure 5: (a and b) SEM and TEM images of $\mathrm{Fe}_{3} \mathrm{O}_{4}$ nanoparticles; (c and d) TEM images of four nanoparticles ( $\theta$ is the angle over which the copper grid is titled). SEM - Scanning electron microscopy; TEM - Transmission electron microscope with high surface area and oriented attachment structure have been successfully fabricated in the presence of PVP. The important role of PVP for the formation of MMNs and oriented attachment structure as a capping agent is widely studied. They have shown that in the presence of PVP, with increasing of heating temperature, nanoparticles slowly self-assemble with each other to form the magnetite spherical-aggregated particles. On the other hand, if no PVP is added into reaction solution, these nanoparticles are aggregated in random morphology, which results in irregular agglomerates. ${ }^{[61]}$ In addition, some other surfactants such as sodium bis(2-ethylhexyl) sulfosuccinate (AOT), ${ }^{[51,63]}$ $\mathrm{SDS}$, and CTAB and in some cases the mixture of two surfactants are used as modifiers simultaneously. Zheng et $a l .{ }^{[51]}$ fabricated ferromagnetic magnetite nanoparticles with a diameter of around $30 \mathrm{~nm}$ in the presence of AOT as a surfactant and hydrazine as reducing agent. However, the saturation magnetization of magnetite nanoparticles is reported $3.69 \mathrm{emu} / \mathrm{g}$ and this $\mathrm{Ms}$ is much smaller than those reported by other researches. ${ }^{[31,64]}$ The authors are believed that the noncollinear structure is the reason for reduction of magnetic moment, which originates from the pinning of the surface spins and the surface-coated surfactant.

Despite using a single surfactant as a capping or protective agent that discussed before, some other researchers reported the mixture of surfactants as more efficient modifiers for synthesis of magnetite through SFM. Yan et al. ${ }^{[53]}$ have shown modified SFM using the mixed surfactants of SDS and PEG. In addition, SDS or PEG is used alone to prepare the magnetite nanoparticles under similar reaction conditions. From Figure $6 \mathrm{a}$ and $\mathrm{b}$, it can be seen that MMNs prepared with the mixture of SDS (4.0 $\mathrm{mmol})$ and PEG (0.4 g, $\sim 7 \mathrm{mmol})$ are achieved. Furthermore, Figure $6 \mathrm{c}$ and $\mathrm{d}$ shows the TEM images of magnetite

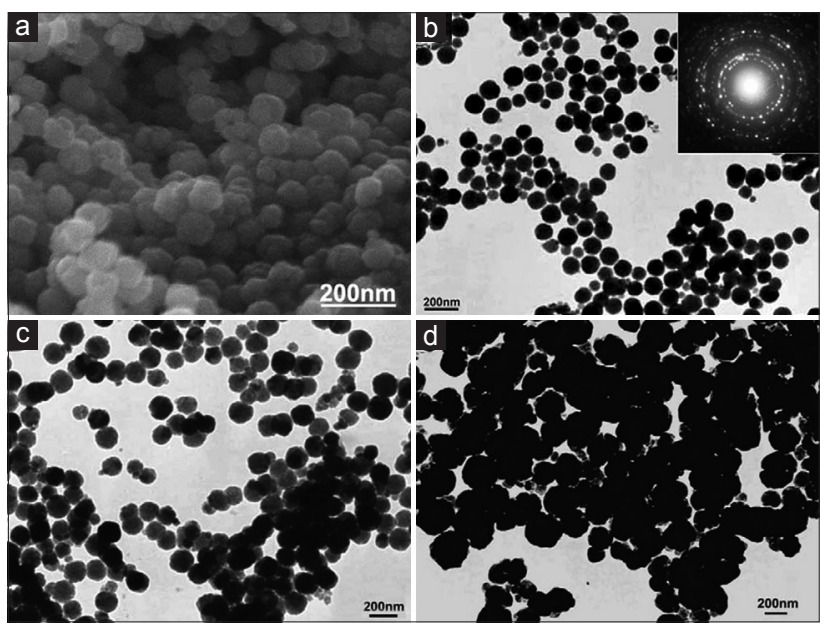

Figure 6: The SEM (a) and TEM (b) images of $\mathrm{Fe}_{3} \mathrm{O}_{4}$ nanoparticles prepared with the mixture of SDS $(4.0 \mathrm{mmol})$ and PEG $(0.4 \mathrm{~g}, \sim 7 \mathrm{mmol}$ and TEM (c and d) images of $\mathrm{Fe}_{3} \mathrm{O}_{4}$ nanoparticles synthesized with different protective agents under typical reaction conditions. (c) $4.0 \mathrm{mmol}$ of SDS. (d) $0.4 \mathrm{~g}(\sim 7.0 \mathrm{mmol}$ of repeating units) of PEG. SEM - Scanning electron microscopy, TEM - Transmission electron microscope; PEG - Polyethylene glycol 
nanoparticles obtained by SDS and PEG alone as protecting agents, respectively. The uniformity of as-prepared SFNs that synthesized by SDS and PEG alone is much worse than the sample prepared using the mixture of both surfactants. The mean size of fabricated SFNs by mixture of SDS and PEG is around $80 \mathrm{~nm}$. Table 1 summarizes solvothermal synthesis of magnetite nanoparticles with various fabrication conditions.

\section{Potential applications of magnetite $\left(\mathrm{Fe}_{3} \mathrm{O}_{4}\right)$}

In this section, we concentrated on potential applications of magnetite that synthesized by SFM. As discussed in the previous sections, by manipulating the key parameters of SFM, it is possible to synthesize functional nanoparticles with controllable size and shape because of their fundamental scientific significance and broad technological applications.

\section{Biomedical applications}

Magnetite $\left(\mathrm{Fe}_{3} \mathrm{O}_{4}\right)$ nanoparticles in the biomedical applications have attracted the attention of researchers around the world as potential materials for carriers of drug and gene delivery, DNA, biomolecules separation, hyperthermia, and contrast agents for magnetic resonance imaging (MRI). For SFNs that want to be used in biomedical applications, water-dispersible particles with controllable sizes, fast magnetic response, and favorable surface properties are in demand. In cancer therapy, the size of SFNs is limited by the primary immunogenic system. Particles with sizes more than $200 \mathrm{~nm}$ tend to be eliminated by reticuloendothelial system (RES). On the other hand, particles with sizes smaller than $10 \mathrm{~nm}$ are rapidly excreted by the kidneys. Therefore, SFNs in the range of $10-100 \mathrm{~nm}$ have the longest circulation time. ${ }^{[76-78]}$

Liu et al..$^{[33]}$ synthesized high water-dispersible MMNs by a modified SFM. The mean particle size of products can easily be tuned over a wide range of $80-410 \mathrm{~nm}$ by varying the concentration of ferrite chloride and trisodium citrate as a stabilizer. Moreover, these SFNs have shown a low cytotoxicity, a good biocompatibility, and a high capacity for efficient and suitable enrichment of trace peptides, which make them promising candidates for applications in various bio-related fields, such as cell imaging and cell sorting. Another important aspect in the application of magnetite nanoparticles as a drug delivery agent is to accumulate the particles around the target tissue as a targeted drug delivery system and controlled release behavior. ${ }^{[79-81]}$ For instance, Kim et al. ${ }^{[82]}$ have fabricated porous magnetite particles by surfactant-free SFM with noncontact heat-assisted drug-releasing property to assess its controlled release and hyperthermia potentials simultaneously. Porous magnetite is prepared using iron chloride, sodium acetate, and EG. The drug-releasing ability of as-synthesized magnetite particles is confirmed by evaluating their release of ibuprofen (IBU) as a model drug. Results have shown that the drug release of the IBU-loaded magnetite particles was faster with heating assistance using alternating current magnetic field. Moreover, by applying a magnetic field with $6.7,7.8$, and $8.3 \mathrm{kA} / \mathrm{m}$ magnitudes at $120 \mathrm{kHz}$ frequency to porous magnetite for $1800 \mathrm{~S}$, an increase in temperature up to $30.1^{\circ} \mathrm{C}, 43.9^{\circ} \mathrm{C}$, and $76.9^{\circ} \mathrm{C}$ is observed, respectively, which can be applied in both mild hyperthermia and thermo-ablation cases.

Guo et al. ${ }^{[83]}$ synthesized mesoporous single-crystal magnetite nanoparticles via SFM and assessed the loading and controlled release capabilities of the nanoparticles with doxorubicin as an anticancer drug. In another study, SFM is used to synthesize ultrasmall monodisperse magnetite nanoparticles, in which iron acetylacetonate (Fe[acac $]_{3}$ ) acted as the iron source, n-octylamine as the reductant, and n-octanol as the solvent as MRI contrast agents. As high-performance MRI contrast agents, the relaxation efficiency of the obtained magnetite nanoparticles depending on the particle size was investigated in CTAB aqueous solution. The $\mathrm{r} 2 / \mathrm{r} 1$ ratio clearly increases as the particle size decreases because $\mathrm{T} 1$ is influenced by the size reduction more significantly than T2, indicating that the prepared magnetite nanoparticles are all T2 contrast agents with high efficiency at $14.1 \mathrm{~T}$, and the MRI efficiency is enhanced with the particle size reduction from

\begin{tabular}{|c|c|c|c|c|c|c|c|}
\hline Solvent & Surfactant & Reductant & $\begin{array}{c}\text { Magnetization } \\
\text { saturation }(\mathrm{emu} / \mathrm{g})\end{array}$ & $\begin{array}{c}\text { Particle } \\
\text { size }(\mathrm{nm})\end{array}$ & Temperature $\left({ }^{\circ} \mathrm{C}\right)$ & Time (h) & References \\
\hline$\overline{\mathrm{EG}}$ & PEG & $\mathrm{NaAc}$ & 81.9 & 200 & 200 & 8 & {$[31]$} \\
\hline EG & - & $\mathrm{NaAc}$ & 78.9 & 250 & 200 & 10 & {$[33]$} \\
\hline Water & AOT & Hydrazine hydrate & 3.7 & 27 & 160 & 10 & {$[51]$} \\
\hline Water-alcohol & PVP & $\mathrm{H}_{2} \mathrm{O}_{2}$ & 71.7 & 48 & 230 & 24 & {$[52]$} \\
\hline EG & SDS-PEG & $\mathrm{NaAc}$ & - & 80 & 180 & 72 & {$[53]$} \\
\hline EG & PVP & Acetate & 42.8 & 100 & $140-145$ & 36 & {$[61]$} \\
\hline Ethanol & PVP & Hydrazine hydrate & 71 & $30-40$ & 180 & 6 & {$[62]$} \\
\hline EG & CTAB & $\mathrm{NaAc}$ & 86.3 & $230-250$ & 200 & 12 & {$[64]$} \\
\hline EG & - & $\mathrm{NaAc}$ & 89.4 & $200-250$ & 200 & 12 & {$[65]$} \\
\hline
\end{tabular}

EG - Ethylene glycol; PEG - Polyethylene glycol; AOT - Sodium bis(2-ethylhexyl) sulfosuccinate; PVP - Polyvinylpyrrolidone; SDS - Sodium dodecyl sulfate; CTAB - Cetyltrimethyl ammonium bromide 
$6 \mathrm{~nm}$ to $4 \mathrm{~nm} \cdot{ }^{[84]}$ Vargas-Osorio et al. ${ }^{[85]}$ have assessed magnetite-carbon nanoparticles with core-shell structure, which have been synthesized through SFM, for both hyperthermia and MRI in brain biomedical applications. Despite mentioned applications, the biocompatibility of as-prepared nanoparticles has been assessed and the results showed that their biological performance shows very good biocompatibility and labeling capacities after incubation in rat mesenchymal stem cells. Table 2 summarizes potential magnetite nanoparticles, which have been synthesized via SFM, for biomedical applications.

\section{Adsorbent applications}

Another potential application of magnetite nanoparticles is using them as absorbents of heavy metals as they can be separated from the medium via a simple magnetic process. Kumari et al. ${ }^{\left[{ }^{[6]}\right.}$ have applied a simple and one-pot SFM to synthesize magnetite nanospheres with hollow interiors to remediate $\mathrm{Cr}^{6+}$ and $\mathrm{Pb}^{2+}$ from water. Results revealed that the Langmuir adsorption capacities of magnetite nanospheres were $\sim 9$ and $\sim 19 \mathrm{mg} / \mathrm{g}$ for $\mathrm{Cr}^{6+}$ and $\mathrm{Pb}^{2+}$, respectively. Yan et al. ${ }^{[87]}$ presented a one-step SFM to prepare the nanocomposite of magnetite/bentonite through the reaction of ferric chloride, sodium acetate, and ethylenediamine in EG with an additive of natural bentonite powder simultaneously. The synthesized nanocomposite is used to adsorb heavy metals $\left(\mathrm{Pb}^{2+}, \mathrm{Cd}^{2+}\right.$, and $\left.\mathrm{Cu}^{2+}\right)$ in aqueous solution. The surface area and total pore volume of the magnetite/bentonite nanocomposites were all larger than those in the natural bentonite and pure magnetite. The adsorption capacities on the basis of Langmuir model were $81.5,21.7$, and $19.6 \mathrm{mg} / \mathrm{g}$ for $\mathrm{Pb}^{2+}, \mathrm{Cd}^{2+}$, and $\mathrm{Cu}^{2+}$, respectively.

\section{Lithium-ion batteries}

One of the significant successes of modern materials electrochemistry is applying SFNs in rechargeable lithium-ion batteries, which have been extensively used in electronics, cell phones, and laptop computers. ${ }^{[88-90]}$ Magnetite is a very promising candidate as anode material in rechargeable lithium-ion batteries, which is because of its ability to store up to eight lithium per formula unit $\left(\mathrm{Fe}_{3} \mathrm{O}_{4+} 8 \mathrm{Li}^{+}+8 \mathrm{e}^{-} \leftrightarrow 4 \mathrm{Li}_{2} \mathrm{O}+3 \mathrm{Fe}\right)$ via reversible reactions, resulting in a high theoretical capacity of $924 \mathrm{mAhg}^{-1}$. Moreover, advantages such as low cost, ease

\begin{tabular}{lccc}
\hline \multicolumn{4}{c}{$\begin{array}{c}\text { Table 2: Summary of potential magnetite biomedical } \\
\text { applications synthesized by solvothermal }\end{array}$} \\
\hline $\begin{array}{l}\text { Application } \\
\text { (in vitro) }\end{array}$ & $\begin{array}{c}\text { Magnetization } \\
\text { saturation (emu/g) }\end{array}$ & $\begin{array}{c}\text { Particle } \\
\text { size (nm) }\end{array}$ & References \\
\hline $\begin{array}{l}\text { Hyperthermia; } \\
\text { drug delivery }\end{array}$ & 79 & 300 & {$[82]$} \\
$\begin{array}{l}\text { Drug delivery } \\
\text { MRI }\end{array}$ & 65 & 70 & {$[83]$} \\
& 63 & 6 & {$[84]$} \\
\hline
\end{tabular}

MRI - Magnetic resonance imaging of synthesis, and environmental friendliness make it a desirable candidate for large-scale commercial applications for rechargeable lithium-ion batteries. ${ }^{[1,92]}$ However, using SFNs including magnetite as an anode material is limited by low initial Coulombic efficiency and the huge volume change during lithium-ion insertion/extraction that causes the poor cyclic property and rapid capacity degradation. During lithium-ion insertion/extraction process, the huge volume change not only pulverizes the initial structure but also destroys the electrical connection between anode materials and current collectors, therefore leading to undeveloped reversibility and poor cycling performance. ${ }^{[93,94]}$ Hence, it is of great interest to develop new approaches to relieve the volume change, maintain the integrity of the electrodes, and consequently improve the cycling stability and reversible capacity of the electrode. ${ }^{\text {[95] }}$ An effective strategy to circumvent above problems that hard to deal with is to develop hybrid electrodes consisted of SFNs and carbon. ${ }^{[96]}$ These SFNs/carbon composites electrodes can provide enough space to accommodate the huge volume change during the lithiation/delithiation process and maintain the integrity of the composite electrodes.

Chen et al. ${ }^{[97]}$ have developed a high pressure and temperature-based SFM for fabricating magnetite with carbon as a composite anode for lithium-ion batteries. Due to high pressure and temperature of SFM medium, in situ carbonization of organic components inside the medium had been occurred and carbon in composite is obtained. Results showed that the sample with $\sim 54.6 \%$ carbon at current density of $50 \mathrm{~mA} / \mathrm{g}$ has achieved a capacity of $\sim 610 \mathrm{mAhg}^{-1}$ after 100 cycles. Zhang et al. ${ }^{[98]}$ have adopted SFM as a facile fabrication strategy to design $\mathrm{Fe}_{3} \mathrm{O}_{4} /$ rebar graphene composite to use as an anode material in lithium-ion batteries. As a consequence, the as-prepared $\mathrm{Fe}_{3} \mathrm{O}_{4} /$ rebar graphene composite displays stable cycling performance $\left(1038 \mathrm{mAhg}^{-1}\right.$ after 100 cycles at $\left.100 \mathrm{mAg}^{-1}\right)$.

\section{Conclusion}

Main solvothermal synthetic factors to achieve the morphology control of well-defined spinel ferrites have been discussed. Moreover, $\mathrm{Fe}_{3} \mathrm{O}_{4}$ is chosen as a case study and recent developments of $\mathrm{Fe}_{3} \mathrm{O}_{4}$ nanoparticles, which are synthesized via solvothermal route, have been considered. Compared with traditional synthesis routes, solvothermal methods are at an early stage of investigations despite that the potential of solvothermally fabricated nanomaterials has been clearly reported by some excellent studies. Using SFM with tremendous characteristics allows for the precise control over the size, shape distribution, and crystallinity of SFNs or nanostructures. By changing certain key experimental factors such as reaction temperature, reaction time, solvent type, surfactant type, and precursor type, these characteristics can be altered. An accurate understanding of these factors and mechanisms will promote the design 
of new synthesis routes for SFNs with desired properties, which can be applied for practical applications such as storage, catalysis, bio-imaging, and therapy.

\section{Financial support and sponsorship}

None.

\section{Conflicts of interest}

There are no conflicts of interest.

\section{References}

1. Caruso F, Spasova M, Susha A, Giersig M, Caruso RA. Magnetic Nanocomposite Particles and Hollow Spheres Constructed by a Sequential Layering Approach. Chem Mater 2001;13:109-16.

2. Maggioni G, Vomiero A, Carturan S, Scian C, Mattei G, Bazzan $\mathrm{M}$, et al. Structure and optical properties of Aupolyimide nanocomposite films prepared by ion implantation. Appl Phys Lett 2004;85:5712-4.

3. Bogle KA, Dhole SD, Bhoraskar VN. Silver nanoparticles: synthesis and size control by electron irradiation. Nanotechnology 2006;17:3204-8.

4. Gangopadhyay P, Kesavamoorthy R, Bera S, Magudapathy P, Nair KG, Panigrahi BK, et al. Optical absorption and photoluminescence spectroscopy of the growth of silver nanoparticles. Phys Rev Lett 2005;94:047403.

5. Hassanzadeh-Tabrizi SA, Behbahanian S, Amighian J. Synthesis and magnetic properties of $\mathrm{NiFe} 2-\mathrm{xSmxO} 4$ nanopowder. $\mathrm{J}$ Magn Magn Mater 2016;410:242-7.

6. Foroughi F, Hassanzadeh-Tabrizi SA, Amighian J. A designed magnetic $\mathrm{CoFe} 2 \mathrm{O} 4$-hydroxyapatite core-shell nanocomposite for Zn (II) removal with high efficiency. Ceram Int 2015;41:6844-50.

7. Chen C, Gunawan P, Xu R. Self-assembled Fe3O4-layered double hydroxide colloidal nanohybrids with excellent performance for treatment of organic dyes in water. J Mater Chem 2011;21:1218-25.

8. Tavakoli H, Sarraf-Mamoory R, Zarei AR. Solvothermal synthesis of copper nanoparticles loaded on multi-wall carbon nanotubes as catalyst for thermal decomposition of ammonium perchlorate. J Adv Mater Process 2015;3:3-10.

9. Chen FH, Zhang LM, Chen QT, Zhang Y, Zhang ZJ. Synthesis of a novel magnetic drug delivery system composed of doxorubicin-conjugated $\mathrm{Fe} 3 \mathrm{O} 4$ nanoparticle cores and a PEG-functionalized porous silica shell. Chem Commun (Camb) 2010;46:8633-5.

10. Foroughi F, Hassanzadeh-Tabrizi SA, Bigham A. In situ microemulsion synthesis of hydroxyapatite-mgFe2O4 nanocomposite as a magnetic drug delivery system. Mater Sci Eng C Mater Biol Appl 2016;68:774-9.

11. Raj K, Moskowitz B, Casciari RJ. Advances in ferrofluid technology. Magn Magn Mater 1995;149:174-80.

12. Jun YW, Seo JW, Cheon J. Nanoscaling laws of magnetic nanoparticles and their applicabilities in biomedical sciences. Acc Chem Res 2008;41:179-89.

13. Ferrari M. Cancer nanotechnology: Opportunities and challenges. Nat Rev Cancer 2005;5:161-71.

14. Huh YM, Jun YW, Song HT, Kim S, Choi JS, Lee JH, et al. In vivo magnetic resonance detection of cancer by using multifunctional magnetic nanocrystals. J Am Chem Soc 2005; 127:12387-91.

15. Son SJ, Reichel J, He B, Schuchman M, Lee SB. Magnetic nanotubes for magnetic-field-assisted bioseparation, biointeraction, and drug delivery. J Am Chem Soc
2005; 127:7316-7.

16. Wang J, Gao M, Wang D, Li X, Dou Y, Liu Y, Pan H. Chemical vapor deposition prepared bi-morphological carbon-coated $\mathrm{Fe} 3 \mathrm{O} 4$ composites as anode materials for lithium-ion batteries. $\mathrm{J}$ Power Sources 2015;282:257-64.

17. Liu XG, Wu ND, Cui CY, Zhou PP, Sun YP. Enhanced rate capability and cycling stability of core/shell structured $\mathrm{CoFe} 2 \mathrm{O} 4 /$ onion-like $\mathrm{C}$ nanocapsules for lithium-ion battery anodes. $\mathrm{J}$ Alloys Compounds 2015;644:59-65.

18. Zhou J, Qin J, Zhang X, Shi C, Liu E, Li J, et al. 2D space-confined synthesis of few-layer MoS2 anchored on carbon nanosheet for lithium-ion battery anode. ACS Nano 2015;9:3837-48.

19. Wang X, Li M, Wang Y, Chen B, Zhu Y, Wu Y. A Zn-NiO rechargeable battery with long lifespan and high energy density. J Mater Chem 2015;3:8280-3.

20. Wang B, Cheng JL, Wu YP, Wang D, He DN. Porous NiO fibers prepared by electrospinning as high performance anode ma- terials for lithium ion batteries. Electrochem Commun 2012;23:5-8

21. Willard MA, Nakamura Y, Laughlin DE, McHenry ME. Magnetic properties of ordered and disordered spinel-phase ferrimagnets. $\mathrm{J}$ Am Ceramic Soc 1999;82:3342-6.

22. Harrison JR, Purnis A. Magnetic properties of the magnetitespinel solid solution: Curie temperatures, magnetic susceptibilities, and cation ordering. Am Mineralogist 1996;81:375-84.

23. Shokrollahi H, Avazpour L. Influence of intrinsic parameters on the particle size of magnetic spinel nanoparticles synthesized by wet chemical methods. Particuology 2016;26:32-9.

24. Nadoll P, Angerer T, Mauk JL, French D, Walshe J. The chemistry of hydrothermal magnetite: A review. Ore Geol Rev 2014;61:1-32.

25. Du GH, Liu ZL, Xia X, Chu Q, Zhang SM. Characterization and application of $\mathrm{Fe} 3 \mathrm{O} 4 / \mathrm{SiO} 2$ nanocomposites. J Sol Gel Sci Technol 2006;39:285-91.

26. Azurdia JA, Marchal J, Shea P, Sun HP, Pan XQ, Laine RM. Liquid-Feed Flame Spray Pyrolysis as a Method of Producing Mixed-Metal Oxide Nanopowders of Potential Interest as Catalytic Materials. Nanopowders along the NiO-Al2O3 Tie Line Including (NiO)0.22(A12O3)0.78, a New Inverse Spinel Composition. Chem Mater 2006;18:731-9.

27. Sivakov V, Petersen C, Daniel C, Shen H, Mucklich F, Mathur S. Laser induced local and periodic phase transformations in iron oxide thin films obtained by chemical vapour deposition. Appl Surf Sci 2005;247:513-7.

28. Sakabe Y, Yamashita Y, Yamamoto H. Dielectric properties of nano-crystalline BaTiO3 synthesized by micro-emulsion method. J Eur Ceram Soc 2005;25:2739-42.

29. Fujii T, Matsusue I, Nakatsuka D, Nakanishi M, Takada J. Synthesis and anomalous magnetic properties of $\mathrm{LaFeO} 3$ nanoparticles by hot soap method.Mater Chem Phys 2011;129:805-9.

30. Shi D, Hu GH, Li RK. Concept of nano-reactor for the control of the selectivity of the free radical grafting of maleic anhydride onto polypropylene in the melt. Chem Eng Sci 2006;61:3780-4.

31. Deng $\mathrm{H}, \mathrm{Li} \mathrm{X}$, Peng $\mathrm{Q}$, Wang $\mathrm{X}$, Chen J, Li $\mathrm{Y}$, et al. Monodisperse magnetic single-crystal ferrite microspheres. Angew Chem Int Ed Engl 2005;44:2782-5.

32. Ansari M, Bigham A, Hassanzadeh-Tabrizi SA, Abbastabar Ahangar $\mathrm{H}$. Synthesis and characterization of $\mathrm{Cu}_{0.3} \mathrm{Zn}_{0.5} \mathrm{Mg}_{0.2} \mathrm{Fe}_{2} \mathrm{O}_{4}$ nanoparticles as a magnetic drug delivery system. J Magn Magn Mater 2017;439:67-75. 
33. Liu J, Sun Z, Deng Y, Zou Y, Li C, Guo X, et al. Highly water-dispersible biocompatible magnetite particles with low cytotoxicity stabilized by citrate groups. Angew Chem Int Ed Engl 2009;48:5875-9.

34. Rabenau A. The role of hydrothermal synthesis in preparative chemistry. Angew Chem Int Ed 1985;24:1026-40.

35. Feng $\mathrm{S}, \mathrm{Xu} \mathrm{R}$. New materials in hydrothermal synthesis. Acc Chem Res 2001;34:239-47.

36. Walton RI. Subcritical solvothermal synthesis of condensed inorganic materials. Chem Soc Rev 2002;31:230-8.

37. Cundy CS, Cox PA. The hydrothermal synthesis of zeolites: History and development from the earliest days to the present time. Chem Rev 2003;103:663-702.

38. Tang KB, Qian YT, Zeng JH, Yang XG. Solvothermal route to semiconductor nanowires\}. Adv Mater 2003;15:448-50.

39. Zhu YJ, Chen F. Microwave-assisted preparation of inorganic nanostructures in liquid phase. Chem Rev 2014;114:6462-555.

40. Lai J, Niu W, Luque R, Xu G. Solvothermal synthesis of metal nanocrystals and their applications. Nano Today 2015;10:240-67.

41. Niu W, Zhang L, Xu G. Shape-controlled synthesis of single-crystalline palladium nanocrystals. ACS Nano 2010;4:1987-96.

42. Zhang L, Niu W, Gao W, Majeed S, Liu Z, Zhao J, et al. Synthesis and electrocatalytic properties of tetrahexahedral, polyhedral, and branched Pd@Au core-shell nanocrystals. Chem Commun (Camb) 2013;49:8836-8.

43. Arancon RA, Lin SH, Chen G, Lin CK, Lai J, Xu G, et al. Nanoparticle tracking analysis of gold nanomaterials stabilized by various capping agents. RSC Adv 2014;4:17114-9.

44. Kang D, Yu X, Ge M, Song W. One-step fabrication and characterization of hierarchical $\mathrm{MgFe} 2 \mathrm{O} 4$ microspheres and their application for lead removal. Microporous Mesoporous Mater 2015;207:170-8.

45. Penchal Reddy M, Mohamed AM. One-pot solvothermal synthesis and performance of mesoporous magnetic ferrite MFe2O4 nanospheres. Microporous Mesoporous Mater 2015;215:37-45.

46. Xu R, Pang W, Huo Q. Hydrothermal and solvothermal syntheses. In: Feng S, Guanghua L, editors. Modern Inorganic Synthetic Chemistry (2 $\left.{ }^{\text {nd }}\right)$. Netherlands: Elsevier; 2011.

47. Wang L, Ren J, Wang Y, Liu X, Wang Y. Controlled synthesis of magnetic spinel-type nickel ferrite nanoparticles by the interface reaction and hydrothermal crystallization. J Alloys Compounds 2010;490:656-60.

48. Nejati K, Zabihi R. Preparation and magnetic properties of nano size nickel ferrite particles using hydrothermal method. Chem Cent J 2012;6:23.

49. Kodama RH, Berkowitz AE, McNiff EJ Jr., Foner S. Surface spin disorder in niFe2O4 nanoparticles. Phys Rev Lett 1996;77:394-7.

50. Lei W, Liu Y. Synthesis and magnetic properties of octahedral Fe3O4 via a one-pot hydrothermal route. Phys Let 2017;381:314318.

51. Zheng Y, Cheng Y, Bao F, Wang Y. Synthesis and magnetic properties of $\mathrm{Fe} 3 \mathrm{O} 4$ nanoparticles. Mater Res Bull 2006;41:525-9.

52. Xiong Y, Ye J, Gu X, Chen Q. Synthesis and assembly of magnetite nanocubes into flux-closure rings. J Phys Chem C 2007;111:6998-7003.

53. Yan A, Liu X, Qiu G, Wu H, Yi R, Zhang N, et al. Solvothermal synthesis and characterization of size-controlled $\mathrm{Fe} 3 \mathrm{O} 4$ nanoparticles. J Alloys Compounds 2008;458:487-91.

54. Yang T, Shen C, Li Z, Zhang H, Xiao C, Chen S, et al. Highly Ordered Self-Assembly with Large Area of Fe3O4 Nanoparticles and the Magnetic Properties. J Phys Chem B 2005;109:23233-6.

55. Baruwati B, Manorama SV. Monodispersed NiFe2O4 nanoparticles: Nonaqueous synthesis and characterization. Mater Chem Phys 2008;112:631-6.

56. Deng H, Chen H, Li H. Synthesis of crystal MFe2O4 (M= Mg, $\mathrm{Cu}, \mathrm{Ni})$ microspheres. Mater Chem Phys 2007;101:509-13.

57. Shi R, Liu X, Gao G, Yi R, Qiu G. Large-scale synthesis and characterization of monodisperse $\mathrm{Fe} 3 \mathrm{O} 4$ nanocrystals. J Alloys Compounds 2009;485:548-53.

58. Nonkumwong J, Ananta S, Jantaratana P, Phumying S, Maensiri S, Srisombat L. Phase formation, morphology and magnetic properties of $\mathrm{MgFe} 2 \mathrm{O} 4$ nanoparticles synthesized by hydrothermal technique. J Magn Magn Mater 2015;381:226-34.

59. Shen Y, Wu Y, Li X, Zhao Q, Hou Y. One-pot synthesis of $\mathrm{MgFe} 2 \mathrm{O} 4$ nanospheres by solvothermal method. Mater Lett 2013;96:85-8.

60. Ge J, Hu Y, Biasini M, Beyermann WP, Yin Y. Superparamagnetic magnetite colloidal nanocrystal clusters. Angew Chem Int Ed Engl 2007;46:4342-5.

61. Zhu YF, Zhao WR, Chen HR, Shi JL. A Simple One-Pot SelfAssembly Route to Nanoporous and Monodispersed Fe3O4 Particles with Oriented Attachment Structure and Magnetic Property. J Phys Chem C 2007;111:5281-5.

62. Lu J, Jiao XL, Chen DR, Li W. Solvothermal Synthesis and Characterization of $\mathrm{Fe} 3 \mathrm{O} 4$ and $\gamma$-Fe2O3 Nanoplates. J Phys Chem C 2009;113:4012-7.

63. Yan H, Zhang JC, You CX, Song XW, Yu BW, Shen Y. Influences of different synthesis conditions on properties of Fe3O4 nanoparticles. Mater Chem Phys 2009;113:46-52.

64. Liu H, Ji S, Zheng Y, Li M, Yang H. Modified solvothermal synthesis of magnetic microspheres with multifunctional surfactant cetyltrimethyl ammonium bromide and directly coated mesoporous shell. Powder Technol 2013;246:520-9.

65. Chae HS, Piao SH, Choi HJ. Fabrication of spherical Fe3O4 particles with a solvothermal method and their magnetorheological characteristics. J Ind Eng Chem 2015;29:129-33.

66. Cornell RM, Schwertmann U. The Iron Oxides: Structure, Properties, Reactions, Occurrences and Uses. $2^{\text {nd }}$ ed. WILEY-VCH, Weinheim: Wiley-VCH; 2006.

67. Sugimoto T, Matijevic;E. Formation of uniform spherical magnetite particles by crystallization from ferrous hydroxide gels. J Colloid Interface Sci 1980;74:227-43.

68. Jolivet JP, Chanéac C, Tronc E. Iron oxide chemistry. From molecular clusters to extended solid networks. Chem Commun 2004:481-3.

69. Li F, Liu J, Evans DG, Duan X. Stoichiometric Synthesis of Pure $\mathrm{MFe} 2 \mathrm{O} 4(\mathrm{M}=\mathrm{Mg}, \mathrm{Co}$, and Ni) Spinel Ferrites from Tailored Layered Double Hydroxide (Hydrotalcite-Like) Precursors. Chem Mater 2004;16:1597-602.

70. Chen X, Deng Z, Li L, Li Y. Hydrothermal synthesis and superparamagnetic behaviors of a series of ferrite nanoparticles. J Inorg Chem 2002;18:460-4.

71. Harris LA, Goff JD, Carmichael AY, Riffle JS, Harburn JJ, Pierre TG, et al. Magnetite nanoparticle dispersions stabilized with triblock copolymers. Chem Mater 2003;15:1367-77.

72. Zhou ZH, Wang J, Liu X, Chan HS. Synthesis of Fe3O4 nanoparticles from emulsions. J. Mater Chem 2001;11:1704-9.

73. Sahoo Y, Cheon M, Wang S, Luo H, Furlani EP, Prasad PN. Field-directed self-assembly of magnetic nanoparticles. J Phys Chem B 2004;108:3380-3.

74. Song Q, Zhang ZJ. Shape control and associated magnetic properties of spinel cobalt ferrite nanocrystals. J Am Chem Soc 
2004;126:6164-8.

75. Hyeon T. Chemical synthesis of magnetic nanoparticles. Chem Commun (Camb) 2003:927-34.

76. Bigham A, Hassanzadeh-Tabrizi SA, Rafienia M, Salehi H. Ordered mesoporous magnesium silicate with uniform nanochannels as a drug delivery system: The effect of calcination temperature on drug delivery rate. Ceram Int 2016;42:17185-91.

77. Hassanzadeh-Tabrizi SA, Bigham A, Rafienia M. Surfactantassisted sol-gel synthesis of forsterite nanoparticles as a novel drug delivery system. Mat Sci Eng C Bio 2016;58:737-41.

78. Hadidi M, Bigham A, Saebnoori E, Hassanzadeh-Tabrizi SA, Rahmati S, Mohammad Alizadeh Z, et al. Electrophoreticdeposited hydroxyapatite-copper nanocomposite as an antibacterial coating for biomedical applications. Surf Coat Technol 2017;321:171-9.

79. Bogart LK, Pourroy G, Murphy CJ, Puntes V, Pellegrino T, Rosenblum D, et al. Nanoparticles for imaging, sensing, and therapeutic intervention. ACS Nano 2014;8:3107-22.

80. Ghadiri S, Hassanzadeh-Tabrizi SA, Bigham A. The effect of synthesis medium on structure and drug delivery behavior of CTAB-assisted sol-gel derived nanoporous calcium-magnesiumsilicate. J Sol Gel Sci Technol 2017;83:229-36.

81. Khamsehashari N, Hassanzadeh-Tabrizi SA, Bigham A. Effects of strontium adding on the drug delivery behavior of silica nanoparticles synthesized by P123-assisted sol-gel method. Mat Chem Phys 2018;205:283-91.

82. Kim S, Katsumata K, Okada K, Matsushita N. Porous magnetite secondary particles prepared by surfactant-free solvothermal method with non-contact heat-assisted drug releasing property. Adv Powder Technol 2016;27:513-20.

83. Guo S, Li D, Zhang L, Li J, Wang E. Monodisperse mesoporous superparamagnetic single-crystal magnetite nanoparticles for drug delivery. Biomaterials 2009;30:1881-9.

84. Tian Y, Yu B, Li X, Li K. Facile solvothermal synthesis of monodisperse $\mathrm{Fe} 3 \mathrm{O} 4$ nanocrystals with precise size control of one nanometre as potential MRI contrast agents. J Mater Chem 2011;21:2476

85. Vargas-Osorio Z, Argibay B, Piñeiro Y, Vázquez-Vázquez C, López-Quintela MA, Sobrino T, et al. Multicore Magnetic Fe3O4@C Beads With Enhanced Magnetic Response for MRI in Brain Biomedical Applications. IEEE Trans. Magn 2016;52:2300604.

86. Kumari M, Pittman CU, Mohan D. Heavy metals [chromium (VI) and lead (II)] removal from water using mesoporous magnetite (Fe3O4) nanospheres. J Colloid Interface Sci 2015;442:120-32.

87. Yan L, Li S, Yu H, Shan R, Du B, Liu T. Facile solvothermal synthesis of $\mathrm{Fe} 3 \mathrm{O} 4 /$ bentonite for efficient removal of heavy metals from aqueous solution. Powder Technol 2016;301:632-40.

88. Goodenough JB, Manthiram A. A perspective on electrical energy storage. MRS Commun 2014;4:135-42.

89. Pushparaj VL, Shaijumon MM, Kumar A, Murugesan S, Ci L, Vajtai R, et al. Flexible energy storage devices based on nanocomposite paper. Proc Natl Acad Sci U S A 2007;104:13574-7.

90. Liu C, Li F, Ma LP, Cheng HM. Advanced materials for energy storage. Adv Mater 2010;22:E28-62.

91. Pang XJ, Zhang J, Qi GW, Dai XH, Zhou JP, Zhang SY. Multi-walled carbon nanotube-reinforced porous iron oxide as a superior anode material for lithium ion battery. J Alloys Compounds 2015;640:8-14.

92. Lu X, Wang R, Bai Y, Chen J, Sun J. Facile preparation of a three-dimensional $\mathrm{Fe} 3 \mathrm{O} 4 /$ macroporous graphene composite for high-performance Li storage. J Mater Chem 2015;3:12031-7.

93. Jing L, Fu A, Li H, Liu J, Guo P, Wang Y, et al. One-step solvothermal preparation of $\mathrm{Fe} 3 \mathrm{O} 4 /$ graphene composites at elevated temperature and their application as anode materials for lithium-ion batteries. RSC Adv 2014;4:59981-9.

94. Abbas SM, Ali S, Niaz NA, Ali N, Ahmed R, Ahmad N. Superior electrochemical performance of mesoporous Fe3O4/ CNT nanocomposites as anode material for lithium ion batteries. J Alloys Compounds 2014;611:260-6.

95. Zeng Z, Zhao H, Lv P, Zhang Z, Wang J, Xia Q. Electrochemical properties of iron oxides/carbon nanotubes as anode material for lithium ion batteries. J Power Sources 2015;274:1091-9.

96. $\mathrm{He} \mathrm{C}, \mathrm{Wu} \mathrm{S}$, Zhao $\mathrm{N}$, Shi $\mathrm{C}$, Liu $\mathrm{E}$, Li J, et al. Carbon-encapsulated fe3O4 nanoparticles as a high-rate lithium ion battery anode material. ACS Nano 2013;7:4459-69.

97. Chen G, Zhou M, Catanach J, Liaw T, Fei L, Deng S, et al. Solvothermal route based in situ carbonization to Fe3O4@ $\mathrm{C}$ as anode material for lithium ion battery. Nano Energy 2014;8:126-32.

98. Zhang G, Li J, Sha J, He C, Liu E, Zhao N, et al. Preparation of $\mathrm{Fe} 3 \mathrm{O} 4 /$ rebar graphene composite via solvothermal route as binder free anode for lithium ion batteries. J Alloys Compounds 2016;661:448-54. 


\section{BIOGRAPHIES}

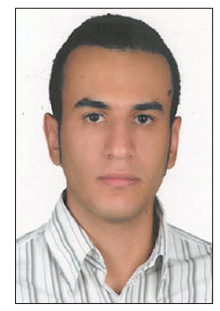

Ashkan Bigham received his M.Sc of Materials Science and Engineering from Islamic Azad University of Najafabad in 2016. Currently he is a research member of Advanced Materials Research Center of Najafabad University under the guidance of Dr. Hassanzadeh-Tabrizi and Dr. Rafienia. His research interests focus on solvothermal synthesis of magnetic materials and fabrication of applicable biomaterials for bone tissue regeneration.

Email: ashkanbigham@gmail.com; ashkanbigham@smt.iaun.ac.ir

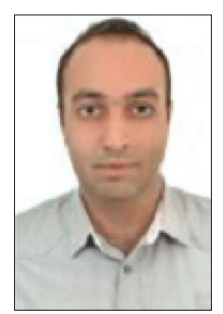

Seyed Ali Hassanzadeh-Tabrizi received his Ph.D. in Materials Science and Engineering from Tarbiat Modares University. He joined Islamic Azad University of Najafabad in 2010, and now is an Associate Professor of Materials Science. His research interests include the design and chemical synthesis of functional nanoparticles and and their biomedical and adsorption related applications.

Email: dralihassanzadeh@gmail.com; hassanzadeh@pmt. iaun.ac.ir

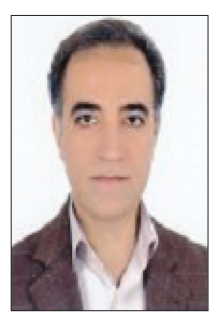

Mohammad Rafienia obtained his B.Sc and both M.Sc and Ph.D. from Isfahan University of Technology and Amir Kabir University of Technology, respectively. He is currently an Associate Professor at Biosensor Research Center of Isfahan University of Medical Sciences. His research expertise is in biomaterials, tissue engineering, and drug delivery.

Email: m_rafienia@med.mui.ac.ir; rafie_med@yahoo.com 